\title{
LEITURA DE POESIA NA EDUCAÇÃO INFANTIL: CONTRIBUIÇÃO PARA A FORMAÇÃO DO FUTURO LEITOR
}

\author{
Joice Naiara Camargo de Abreu (Pedagogia - FACCAT) \\ Prof $^{a}$. Dr ${ }^{\mathrm{a}}$. Luciana Ferreira Leal (Orientadora)
}

\section{RESUMO}

Partindo da premissa de que todas as possibilidades oferecidas a partir da leitura devem ser garantidas no âmbito escolar por meio de uma educação intencional; e de que a poesia infantil proporciona experiências que são possíveis e compatíveis à imaginação da criança e vão além da função didática, este trabalho visa investigar, com base na pesquisa de campo, se as experiências de leitura de textos desse gênero literário, realizadas em sala de aula, na educação infantil, tornam-se aprendizagem significativa que contribuem para formação do futuro leitor apto e crítico e se há alguma indicação para o trabalho com a poesia nas sugestões do Referencial Curricular Nacional para a Educação Infantil. Por fim, identificamos o espaço ocupado pela poesia na escola e algumas possibilidades pedagógicas na educação infantil, uma vez que, refletir sobre as práticas que propiciam o desenvolvimento integral da criança por meio da poesia, pode ser o ponto de partida para incitar o conhecimento poético na escola e em consequência disso pode ocorrer a ampliação nas escolhas e nos gostos pela leitura de poesia desde a primeira infância.

Palavras-chave: Leitura; Literatura Infantil; Poesia Infantil.

\section{LEITURA DE POESIA NA EDUCAÇÃO INFANTIL: PROJETO E ENTREVISTA}

Este trabalho objetiva investigar se o trabalho pedagógico como a poesia, na Educação Infantil, torna-se aprendizagem significativa que contribuem para formação do futuro leitor apto e crítico. Partindo da premissa de que é função da escola, por meio de educação intencional, garantir o acesso da criança à educação poética, que propicia a oportunidade de desenvolver a linguagem oral e escrita, ampliar seu repertório literário, proporcionar exercícios de imaginação e momentos de prazer por meio do lúdico, desenvolvemos a pesquisa na qual investigamos o possível papel formador que a leitura de poesia desempenha em crianças do maternal II, de um Centro Municipal de Educação Infantil (CEMEI) da cidade de Tupã.

Para composição desse projeto, que busca identificar a relevância da poesia na Educação Infantil, usamos da pesquisa bibliográfica, que nos forneceu subsídios teóricos necessários, pois o estudo dessas obras nos possibilita visão mais abrangente acerca do tema. Como afirma Lakatos e Marconi (2010, p.166) "[...] a pesquisa bibliográfica não é mera repetição do que já foi dito ou escrito sob certo assunto, mas propicia o exercício de um tema sob novo enfoque ou abordagem, chegando a conclusões inovadoras". 


\section{SEMINÁRIO DE PESQUISA EM CIÊNCIAS HUMANAS - SEPECH \\ Humanidades, Estado e desafios didático-científicos \\ Londrina, 27 a 29 de julho de 2016}

Realizamos pesquisa de campo, cujo objetivo foi desenvolver hipótese, aumentar a familiaridade do pesquisador com o ambiente, fato ou fenômeno para realização de uma pesquisa futura mais precisa ou modificação e classificação de conceitos (LAKATOS; MARCONI, 2010, p. 166).

Uma das importâncias do ato de ler está em contribuir para a formação de um sujeito emancipado, reflexivo e crítico. De acordo com Lerner (2002, p. 73): "Ler é entrar em outros mundos possíveis. É indagar a realidade para compreendê-la melhor, é se distanciar do texto e assumir postura crítica frente ao que se diz e ao que se quer dizer, é tirar carta de cidadania no mundo da cultura escrita [...]".

Lidar com a literatura traz para as crianças experiências transformadoras, uma vez que $o$ ato de ler requer trabalho de construção de significado do texto, vislumbrando imagens a partir de palavras. É atribuída à leitura múltiplas funções, pois além de aproximar a criança de uma linguagem afetiva, de despertar a fantasia e o lúdico, possibilita que ela faça relação do seu modo de viver, pensar e sentir com os de outras culturas, desempenhando papel extremamente relevante na formação do sujeito. Para Vera Teixeira Aguiar e João Luís Ceccantini (2012, p. 279):

Ler literatura possibilita a qualquer sujeito, independente da faixa etária em que se encontra, um exercício de conhecimento e de construção de si mesmo, das suas emoções, certezas, dúvidas e medos ela pode se revelar como uma possibilidade de dar sentido a tudo que o sujeito sente, vive e percebe.

A poesia coloca-se além do lógico, do convencional, como em um jogo e quando é concebida com liberdade pode gerar nas crianças, e nos leitores de qualquer idade, a capacidade de surpreender-se com mundo. (MARTHA, 2011).

No universo literário, a poesia se configura primordial por seu caráter lúdico e por permitir que o leitor perpasse o nível verbal entrando no campo das representações, se envolvendo no texto e retirando dele um saber: "A criança é levada a preencher as lacunas geradas pela leitura do poema, sendo impulsionada para a interpretação. Em busca do não explícito abre espaço para a diversidade, deslocamentos para outros pontos de vista, uma maior sensibilidade ao outro." (GEBARA, 2012, p. 40).

Contudo, o papel do professor é indispensável nesse processo formador, uma vez que o poder encantador e transformador das palavras não são o suficiente para garantir uma experiência real e significativa com esse gênero singular.

Não basta selecionar bons textos e "despejá-los" sobre as crianças e deixar tudo por conta da magia das palavras. O professor e/ ou mediador torna-se o dinamizador imprescindível para a criança da atmosfera de uma legítima oficina poética. E essa oficina, evidentemente, só se pode realizar em um ambiente de liberdade e criatividade, para que a criança possa se expressar sem bloqueios. (SORRENTI, 2009, p. 20). 


\section{SEMINÁRIO DE PESQUISA EM CIÊNCIAS HUMANAS - SEPECH \\ Humanidades, Estado e desafios didático-científicos \\ Londrina, 27 a 29 de julho de 2016}

O projeto desenvolvido, denominado "A leitura de poemas de Vinícius de Moraes na Educação Infantil" objetivou, por meio de atividades lúdicas, proporcionar as possibilidades que a boa literatura oferece. A obra "A arca de Noé" de Vinicius de Moraes foi escolhida como tema devido à grande contribuição do livro, que reúne poemas infantis com caráter lúdico, que trazem como temática principal os animais, que são extremamente atrativos às crianças dessa faixa etária. A musicalização desses poemas também contribui consideravelmente no processo ensino/aprendizagem.

O público alvo do projeto consisitiu nas crianças regularmente matriculadas no Centro Municipal de Educação Infantil (CMEI) Irene Fontana Bueno, de Tupã, que frequentam a turma Maternal II, com a idade de 3 anos. A sala é composta por 25 crianças. Também enquanto objetivos destacamos: despertar o gosto pelo texto literário de boa qualidade estética; desenvolver a capacidade de escutar; desenvolver o lado lúdico da leitura; ampliar o repertório discursivo; estimular afetividade e sensibilidade e contribuir para a compreensão de que a poesia e a música são obras de arte e formas de linguagem.

$\mathrm{O}$ projeto foi desenvolvido em 15 dias e planejado em etapas diárias que envolveram apresentação do projeto, roda de conversa, leitura e releitura em voz alta dos poemas, discussão dos mesmos, audição da musicalização dos poemas, confecção de cartazes e outros materiais.

A avaliação foi contínua durante todas as etapas do projeto e deu-se por meio do registro de observação. A análise dos registros possibilitou a reflexão das práticas e dos resultados obtidos.

$\mathrm{Na}$ entrevista realizada com a professora da sala, contatou-se que ela realiza diariamente a prática de leitura em voz alta e reconhece sua finalidade e importância no processo de formação da criança. Ela destaca que, ao escolher o texto a ser lido, procura variar os gêneros e enfatiza a predileção das crianças pelos livros com boas ilustrações, porém ressalta que a poesia é trabalhada em datas comemorativas, atribuindo-lhe, assim, caráter utilitário.

No entanto, ao dizer que trabalha com poesia na música, nos trava-línguas e nas parlendas, ela revela reconhecer na presença das rimas e dos ritmos, no jogo com as palavras, a poeticidade, que pode e deve ser usada como ponto de partida no desenvolvimento emocional e poético da criança.

A professora demonstra domínio quando diferencia a linguagem desse gênero específico da dos demais, e quando relata que o contato com o texto poético é propício para ampliar o vocabulário e trabalhar o sentimento, levando em consideração algumas especificidades da poesia.

Contudo, a professora considera a poesia um gênero difícil de ser trabalhado, ela atribui à falta de boa ilustração dos livros de poesia, empecilho para aceitação da parte das crianças. A carência na formação também é considerada um obstáculo ao trabalhar as possibilidades que a poesia oferece no processo de formação. Essas convicções refletem diretamente nas práticas pedagógicas e vão ao encontro dos relatos de diversos professores, e, portanto, podem ser consideradas responsáveis, entre outros aspectos, pela marginalização desse gênero fabuloso. 


\section{SEMINÁRIO DE PESQUISA EM CIÊNCIAS HUMANAS - SEPECH \\ Humanidades, Estado e desafios didático-científicos \\ Londrina, 27 a 29 de julho de 2016}

\section{ANÁLISE DAS ETAPAS DO PROJETO}

No primeiro dia do projeto, a educadora iniciou a roda de conversa, mostrando o livro e falando o nome: "A arca de Noé". Em seguida, ela perguntou se as crianças sabiam o que era a arca de Noé. As crianças não souberam responder. Então ela mostrou a imagem de uma arca e perguntou o que tinha dentro dela. Um acriança respondeu: "animais" e logo várias crianças começaram a listar os animais presentes na figura: "cavalo", "zebra", "girafa", "elefante". Elas disseram que a arca fica no rio e que tem uma casa.

Ao serem questionados sobre quem escreveu o livro, uma única resposta foi obtida: "uma pessoa que mora embaixo do chão". Como não conheciam Vinicius de Moraes, foi lhes apresentado o autor e um breve resumo da sua vida. Dando enfoque no seu trabalho com poemas infantis.

O livro foi passado para as crianças manuseá-lo. A educadora disse que durante as próximas semanas seriam lidos poemas do livro e mostrou o roteiro do projeto. A roda de conversa é propícia para ampliar o universo discursivo das crianças e pode ser organizada para discutir alguns assuntos, intencionalmente, um projeto de construção de um cenário para brincar, um passeio, a leitura de um livro etc. (BRASIL, 1998, p. 138).

A leitura do poema "A arca de Noé", na leitura em voz alta, deu início ao segundo dia do projeto. As crianças se mostraram inquietas. Talvez por não estarem habituadas com poema e por esse, especificamente, ser extenso. Ao terminar a leitura, a educadora perguntou: "quem ouviu o poema?". As crianças responderam: "Eu". Uma criança falou: "Vou ler uma página", ela pegou o livro e ao ver a ilustração disse: "É uma fazenda, tem mais poemas". As crianças foram instigadas a falarem sobre o poema, mas não souberam dizer.

A educadora repetiu a pergunta: "Quem ouviu o poema?" As crianças responderam: "Eu". "Então diz pra mim um bicho que tem no poema?". Ninguém Respondeu. Ao perguntar diretamente pra uma criança, ela respondeu: "Elefante". Outra disse: "Macaco". Na continuação do diálogo, a educadora disse: "Olha, aqui falou de arara, quem conhece arara?", uma criança respondeu: "eu vi uma arara lá no rio", a educadora completou: "Você viu uma arara? O que é arara?", outra criança respondeu: "uma arara azul", a educadora pergunta para confirmar a resposta: "uma o quê?", a criança respondeu: "Uma arara azul", educadora: "Uma arara azul?", a criança disse: "Sim".

As crianças se apoiaram em experiências vividas quando fazem referência ao Blue, uma arara azul, personagem do filme "Rio". De acordo com Gonçalves (2008, p. 7), “... é importante dar voz à criança para que ela possa refletir, fazer associações, relações entre a vida, as idéias e os fatos que o texto apresenta e, assim, possa dar significado ao texto e ampliar sua visão da realidade."

A postura da educadora é compatível com as orientações presentes no Referencial Curricular Nacional para Educação Infantil, que ressaltam a importância do professor como apoio no desenvolvimento verbal da criança:

Cabe ao professor, atento e interessado, auxiliar na construção conjunta das falas das crianças para torná-las mais completas e complexas. Ouvir 


\section{SEMINÁRIO DE PESQUISA EM CIÊNCIAS HUMANAS - SEPECH \\ Humanidades, Estado e desafios didático-científicos \\ Londrina, 27 a 29 de julho de 2016}

atentamente o que a criança diz para ter certeza de que entendeu o que ela falou, podendo checar com ela, por meio de perguntas ou repetições, se entendeu mesmo o que ela quis dizer, ajudará a continuidade da conversa. (BRASIL, 1998, p. 136).

O poema "O pato" foi trabalhado no quarto dia do projeto. Antes de iniciar a leitura, a educadora perguntou se alguém conhecia o poema do pato, elas responderam que não. Logo no início da leitura, uma criança começou recitar junto com a educadora, e no final foi possível observar que várias crianças já conheciam o poema. Foi uma leitura muito agradável, a participação das crianças ficou explícita e se confirmou por meio da interpretação, em que a maioria participou, elencando os atos realizados pelo pato e as consequências. Algumas das respostas obtidas foram: "caiu no cavalo", "um calo", "ficou engasgado", "surrou a galinha", "foi para na panela".

Ficou claro o prazer das crianças ao ouvirem a música "O pato". No primeiro momento, elas acompanharam a música com palmas e, em seguida, todos dançaram de forma livre e alegre. Essa experiência comprova a definição dada por Neusa Sorrenti (2009, p. 104): "A poesia é para ser lida, ouvida, cantada, sentida, vivenciada."

No quinto dia, o poema trabalhado foi "A galinha d'angola". Ao mostrar o livro, a educadora perguntou: "do que será que vai falar o poema de hoje?”, uma criança disse: "galinha pintadinha", outra disse: "galinha da angola", mais uma vez elas se apoiam naquilo que já sabem. A leitura foi realizada e as crianças pediram para ser repetida. A atividade de construção do cartaz - texto ditado pelas crianças - foi realizada com a intenção de proporcionar a elas uma situação onde se faz necessário a escrita. Ao iniciar a atividade, a educadora passou as comandas e esclareceu que o texto seria escrito para que elas não esquecessem e para ler sempre que necessário, fazendo assim a relação com a prática social da escrita. Durante a atividade, foi possível observar que a educadora retomou e releu o que já tinha escrito para auxiliar as crianças na continuação do poema e no controle do ritmo do que estava sendo ditado e do que estava sendo escrito.

Ditar um texto para o professor, para outra criança ou para ser gravado em fita cassete é uma forma de viabilizar a produção de textos antes de as crianças saberem grafá-los. É em atividades desse tipo que elas começam a participar de um processo de produção de texto escrito, construindo conhecimento sobre essa linguagem, antes mesmo que saibam escrever autonomamente. (BRASIL, 1998, 146).

Na hora em que ouviram a música pela primeira vez, as crianças se encontravam sentadas, com o ritmo contagiante, logo começaram a balançar a cabeça. Em um segundo momento, elas se levantaram e dançaram ao ritmo da música.

No sexto dia, foi trabalhado o poema "A foca". O envolvimento das crianças foi perceptivo. A música complementou a experiência poética vivida pelas crianças. Foi apresentado também um clipe da música, animado e colorido, muito envolvente.

Em um segundo momento, foi proposto que as crianças organizassem a sequência do poema - um cartaz confeccionado previamente com as partes do poema e um desenho 


\section{SEMINÁRIO DE PESQUISA EM CIÊNCIAS HUMANAS - SEPECH \\ Humanidades, Estado e desafios didático-científicos \\ Londrina, 27 a 29 de julho de 2016}

para identificação - a educadora leu uma parte e as crianças responderam qual a parte seguinte. Depois da montagem do cartaz, foi realizada a leitura do poema completo. Nesse momento, todos se atentaram e participaram. Ana Elvira Luciano Gebara $(2012$, p. 38) considera que:

Se alguém lê um poema para a criança, a melodia, o tom, a forma como se alternam tônicas e átonas, a presença maciça, ou quase imperceptível da pontuação, são percebidos como forma de expressão corporal, pois envolvem a voz e os gestos que acompanham. Se a própria criança está lendo, será a vez de sua voz imprimir sensações que podem ou não se refletir na organização total do que foi lido.

No decorrer do dia ouviram a musicalização e cantaram diversas vezes.

O poema "Os bichinhos e o homem", foi lido no sétimo dia. Antes de iniciar, a educadora perguntou o nome do autor e do livro, as crianças responderam: "Vinicius de Moraes", "Arca de Noé". Ao ver a ilustração, uma criança disse: "olha o mosquito", a educadora completou: "o poema de hoje vai falar de um monte de bichinhos". A leitura foi realizada e no final teceram comentários sobre quais bichos gostaram e alguns relatos pessoais foram compartilhados: "gostei da borboleta”, “ eu já peguei bicho-de-pé”, "o grilo faz CRI CRI", "tem um monte de besouro na minha casa".

A estrutura do poema se diferencia dos poemas lidos anteriormente, seu tema é extremamente harmonioso com o universo infantil, já que trata de insetos, seres que aguçam a atenção e a curiosidade dos pequenos. Esse momento expressa a função da poesia, segundo Gonçalves (2008, p. 5):

[...] a poesia tem uma importante função no desenvolvimento da personalidade infantil, uma vez que ela permite a comunicação da criança com a realidade, possibilita a investigação do real, ampliando o entendimento e a experiência de mundo através da palavra. Mas, para isso, a sua linguagem, os seus temas precisam estar em harmonia com a vivência infantil para que possa cumprir sua função simbólica e só conseguirá cumpri-la, se tiver valor literário, se criar novas linguagens, se respeitar o mundo infantil que tem uma coerência peculiar.

A mudança de comportamento das crianças diante do gênero foi nítida. $O$ avanço em relação à participação pode ser observado tanto na elaboração de hipóteses sobre a leitura que seria realizada, quanto na interpretação dos poemas lidos, as crianças relacionavam a realidade vivenciada por elas com os poemas constantemente.

Por já terem, em algum momento, ouvido algumas das musicalizações, as crianças se identificaram com determinados poemas. Isso pode ser alegado ao cuidado na seleção dos poemas trabalhados, pois respeitar o nível de desenvolvimento da criança e a natureza do poema é igualmente importante e reflete no efeito causado pelo texto. Alguns poemas causaram efeito parecido, talvez pela linguagem adequada, mas não empobrecida, a 


\section{SEMINÁRIO DE PESQUISA EM CIÊNCIAS HUMANAS - SEPECH \\ Humanidades, Estado e desafios didático-científicos \\ Londrina, 27 a 29 de julho de 2016}

interação se deu de modo mais fácil. E resultado foi a repetição e memorização de alguns poemas pelas crianças, de forma natural, só pelo prazer de reviver o momento.

Ao repetir versos, aliterações e sonoridades, a criança, realiza suas primeiras aproximações efetivas com a poesia. Muitas vezes ela será capaz de repetir e apreciar um poema sem mesmo apreender toda a extensão de seu significado. A primeira fase de seu contato com a poesia é, pois, a do domínio das sonoridades. (NEUSA SORRENTI, 2009, p. 20).

Se o sucesso de alguns poemas pode ser atribuído ao fato de já serem conhecido, outros também alcançaram tal êxito por serem novidade e por trazerem surpresa.

Ao longo do registro feito na execução do projeto também foi possível refutar as hipóteses levantadas a respeito das dificuldades relatadas pela professora, como por exemplo, a preferência das crianças por livros com grandes ilustrações, já que durante os quinze dias que decorreu o projeto, o livro ficou à disposição das crianças e em vários momentos alguma criança pegava-o e explorava-o, apesar do mesmo ter pouca ilustração, desprovida de cor, que apenas vem afirmar a linguagem verbal.

Em vários momentos, as crianças pediram que os poemas fossem lidos novamente, na maioria das vezes elas "liam" junto com a educadora.

As crianças, de forma mais imediata que os adultos, percebem, no texto poético, a simultaneidade que ele produz. Porque a cada leitura, como quando assistem a um filme dezenas de vezes ou cantam uma música repetidamente, elas podem expressar, sem métodos analíticos do crítico, as dezenas de elementos que o poema traz e trata. (GEBARA, 2012, p.40).

O sucesso de Vinicius de Moraes, no maternal II, foi tão grande que a leitura não se limitou aos nove poemas selecionados, pois ao ouvirem a musicalização "O Leão", "O Pinguim" e outros, as crianças pediram para que a educadora lesse os poemas, e algumas até memorizaram parte das musicalizações.

É oportuno lembrar que as atividades realizadas com a incumbência de promover a ampliação das experiências vividas pelas crianças possibilitaram que elas refletissem de modo contextualizado, mas sem romper com o clima da brincadeira, contribuindo, assim, para o processo de construção do conhecimento.

\section{CONSIDERAÇÕES FINAIS}

Buscamos refletir acerca do tema abordado no documento normativo da Educação Infantil - Referencial Curricular Nacional para a Educação Infantil - e, apesar de constar algumas indicações de uso de poesia, o gênero é relegado, muitas vezes, é apenas uma opção entre tantas outras. O texto em prosa ocupa um lugar de destaque por haver mais direcionamento para a contação de histórias. No entanto, cabe ressaltar que, essas 


\section{SEMINÁRIO DE PESQUISA EM CIÊNCIAS HUMANAS - SEPECH \\ Humanidades, Estado e desafios didático-científicos \\ Londrina, 27 a 29 de julho de 2016}

orientações devem servir como suporte para as práticas educativas e não como modelo, portanto, o trabalho do professor não deve ser limitado por decorrência dessa indiferença com a poesia.

O papel do professor é, indiscutivelmente, responsável por atenuar ou suprir a distância existente entre a criança e a poesia. Tanto na seleção do texto, na realização da leitura, na relação com o texto, quanto no direcionamento das atividades realizadas, como: interpretação, discussão, etc. Essa postura se faz primordial, principalmente, na Educação Infantil, em que na maior parte do seu curso, a criança não sabe ler de forma autônoma e a necessidade de seguir um modelo (imitar) ainda está tão presente na sua personalidade.

A convivência com textos em ambiente escolar passa a ser o centro de várias questões: como os professores tratam esse material; o que ele representa para os docentes; o quanto ele é utilizado; a possibilidade de circulação desse texto; de que modo ocorre o contato individual com ele. Todos esses aspectos estão influenciando a constituição de uma imagem do que seja a leitura em sua função neste ambiente. As crianças, quando são iniciadas nessa atividade, aprendem num primeiro momento, como ela se desenvolve em ambiente escolar. (GEBARA, 2012, p. 22).

É função do educador promover a aproximação da criança com textos poéticos, de modo que esta possa vivenciar todas as possibilidades que o gênero oferece, porém, para que isso ocorra, de forma positiva, é fundamental que, antes de qualquer coisa, o educador viva todas essas possibilidades, fazendo das suas experiências uma autêntica promoção da literatura.

A poesia não deve ter um caráter utilitário, pelo contrário, a leitura e as atividades propostas com esse gênero devem ter um caráter lúdico, em que a criança tenha a liberdade de brincar e jogar com as palavras, transitando do mundo real ao imaginário, enfatizando seu caráter de literatura. "Quando alguém consegue romper com essa relação de caráter utilitarista, constata-se que a superação é fruto de um trabalho diferenciado que considera a leitura em suas múltiplas funções e desdobramentos, seja em sala de aula, seja em qualquer outro ambiente". (GEBARA, 2012, p. 25).

Em relação à temática não há nada definido, pois quando o desenvolvimento da criança é respeitado e apresentação é realizada com clareza, qualquer assunto pode ser interessante para acriança. (MARTHA, 2011, p.141).

No decorrer do projeto, as hipóteses levantadas acerca da poesia ser um gênero capaz de despertar o interesse de leitores em qualquer faixa etária confirmaram-se tanto com o envolvimento das crianças quanto com o da educadora, tornando a realização do projeto uma adorável surpresa.

Os resultados obtidos foram, no ponto de vista pedagógico, tão positivos que o projeto foi estendido para todas as CMEIs da cidade de Tupã. Proporcionando para, aproximadamente, 900 crianças, de 0 a 3 anos de idade, a experiência de aproximação das peculiaridades da poesia infantil.

Compreendida, portanto, como necessidade relevante na formação leitora, torna-se inegável a responsabilidade do professor frente ao texto e na elaboração do seu trabalho, 


\section{SEMINÁRIO DE PESQUISA EM CIÊNCIAS HUMANAS - SEPECH \\ Humanidades, Estado e desafios didático-científicos \\ Londrina, 27 a 29 de julho de 2016}

tendo bem claro para si mesmo algumas questões: "o que ler", “como ler" e "para que ler", considerando a natureza do aluno.

\section{REFERÊNCIAS}

AGUIAR, V. T; CECCANTINI, J. L. Poesia infantil e juvenil brasileira: uma ciranda sem fim. São Paulo: Cultura Acadêmica, 2012.

BRASIL. Ministério da Educação e do Desporto. Secretaria de Educação Fundamental. Referencial Curricular Nacional para a Educação Infantil. v. III. Brasília: MEC/SEF, 1998.

GEBARA, A. E. L. A poesia na escola: leitura e análise de poesia para crianças. 3. ed. São Paulo: Cortez, 2012.

GONÇALVES, M. L. B. Poesia infantil: uma linguagem lúdica. Congresso Internacional de Leitura e Literatura Infantil e Juvenil. Anais. Porto Alegre: PUC, 2008. Disponível em: $<$ http://www.pucrs.br/edipucrs/CILLIJ/praticas/POESIA_INFANTIL_OK.pdf $>$. Acesso em: 4 jun. 2015.

LAKATOS, E. M; MARCONE, M. Fundamentos de metodologia científica. 7. ed. São Paulo: Editora Atlas, 2010.

LERNER, D. Ler e escrever: o real, o possível e o necessário. Porto Alegre: Artmed, 2002.

MARTHA, A. A. P. Literatura Infantil - A poesia. In: Zanchetta Junior, J. Caderno de Formação: Formação de professores - Didática dos conteúdos. São Paulo: Cultura Acadêmica, 2011.

SORRENTI, N. A poesia vai à escola: reflexões, comentários e dicas de atividades. 2 ed. Belo Horizonte: Autêntica editora, 2009. 